\title{
Unarrested development
}

\section{Despite the threat of rising sea levels, the drive to develop Florida's coastline continues.} Mark Schrope reports.

T he last time sea level rise in Florida was as rapid as some forecasts predict for the coming century, it was about 8,000 years ago and there were Native Americans living on land that now lies beneath the Gulf of Mexico ${ }^{1}$. It's safe to assume their retreat from submerging lands was relatively uncomplicated, thanks to low numbers and a simple lifestyle.

For modern-day Florida, adaptation will be a bit more challenging. More than 90 per cent of the 18.5 million residents of the Sunshine State live on the coast. On both sides of the peninsula, development is almost solid and has continued barely abated despite a nearly record number of major hurricane hits in recent years. To further complicate the matter, Florida's coasts are composed mainly of barrier islands, most of which could be converted to sea floor before the end of the century if sea level rises one metre.

Although the current rate of sea level rise in Florida is at about the global average of around three millimetres per year, a onemetre rise by 2100 isn't outside the range of recent projections ${ }^{2,3}$ (see page 44). According to a 2007 study, if a rise of 58 centimetres were realized by 2050, it would cost Florida $\$ 92$ billion per year owing to losses in tourism and real estate, among other factors, with costs rising exponentially thereafter. By 2060, with a rise of 68 centimetres, 9 per cent of Florida's land area would be gone, including virtually the entire Florida Keys. In addition, 70 per cent of Florida's most populous region, Miami, would be underwater, along with two nuclear reactors, 68 hospitals, 334 public schools and 1,362 hotels, motels and inns ${ }^{4}$.

That vulnerability, combined with its highly concentrated coastal population, means that Florida will be a case study for other states and the world - either in how to prepare for rising sea levels or in what happens if you don't. For now, at least, lack of legislative and public attention to the issue is leading many experts to bet on the latter.

"Right now Florida is showing almost no leadership on responding sensibly to storms and to rising sea level," says Robert Young, a coastal geologist at Western Carolina University in Cullowhee, North Carolina. Orrin Pilkey of Duke University in North Carolina, a well-known

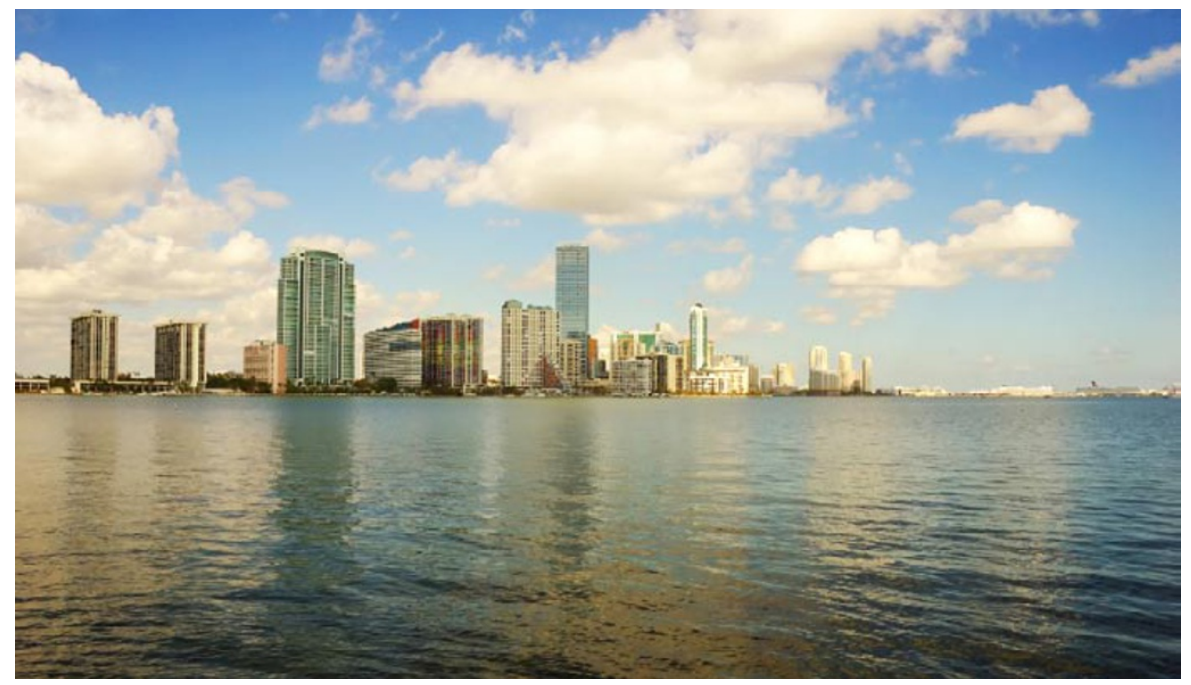

Development along Florida's coastline has continued barely abated despite a nearly record number of major hurricane hits in recent years.

proponent of greater constraints on coastal development, is even more forthright. "I call it an outlaw state," he says. "Florida has been particularly irresponsible and it's going to pay the price very soon."

\section{"It's an outlaw state. Florida has been particularly irresponsible and it's going to pay the price very soon." Orrin Pilkey}

\section{BEACHFRONT ECONOMY}

"The reason Floridians are Floridians is they want to get near the water," says James Murley, an environmental and land-use law expert at Florida Atlantic University in Boca Raton and chair of the Florida Energy and Climate Commission, an organization that deals with the state's energy and climate change policies. "If they wanted to get away from the water, they'd go to Phoenix." Most visitors to the state feel a similar attraction.

When millions of people want desperately to live or vacation near the water, there are billions to be made fulfilling their dreams. Much of the state's economy centres on the $\$ 65$-billion-a-year tourism industry and the tax revenues from development; in turn, much of Florida politics is driven by a historic willingness among those involved in development to contribute to political campaigns they believe will help sustain their profits.

But in spite of the money to be made, many argue that given the threat of sea level rise, Florida needs to make some drastic changes. If temperatures continue to rise, the most intense storms may become more frequent, say scientists ${ }^{5}$, and as sea level also increases, these storms will wreak progressively more havoc. "It makes no sense" to improve infrastructure and to continue building in areas that will have to be abandoned, probably by 2050 , says Harold Wanless, a coastal geologist at the University of Miami.

Others take a more moderate view. Robert Dean, former chair of coastal engineering at the University of Florida in Gainesville, believes that sea level rise in Florida could eventually force some retreats and that more should be done to prepare. But he predicts that in most cases coastal 


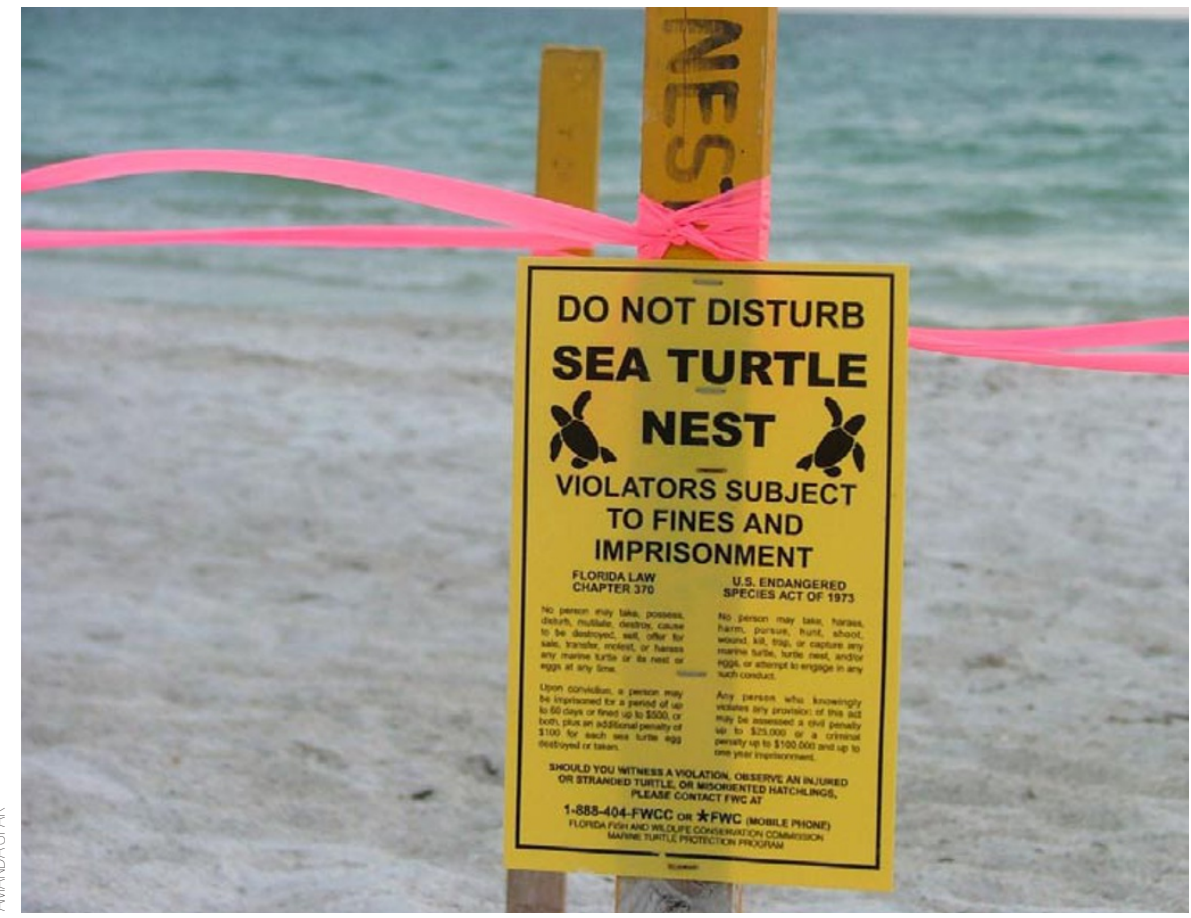

Concerns over beach erosion and degradation of turtle nesting sites have made hard defences unpopular with the public and discouraged by Florida law.

dwellers will find ways to stay put, either by building structures to keep back the water or by adapting buildings to deal with it. "I don't see us abandoning Miami Beach, and I don't see the beach going away," says Dean.

By any account, changing the status quo in Florida will be exceedingly complicated. It is, after all, a place where most communities are less than 100 years old and planning has traditionally focused on short-term profits. Reducing coastal and waterfront development, or asking people to give up their existing homes, would cause major legal battles and would lower profits and taxes, not to mention property values. None of these measures would be popular in a state with multi-billion-dollar budget deficits and an unemployment rate of around 12 per cent, compared to a national average of just over 10 per cent.

\section{SHORING UP}

Faced with the inevitability of rising seas, Floridians have essentially the same choices as people elsewhere: to defend themselves or to retreat. But although the state is ill prepared for a substantial rise in sea level, it does have some experience with keeping water out.

Since the 1970s, Florida has dumped over 53 million cubic metres of sand, brought in from other parts of the state or from offshore, onto hundreds of kilometres of beaches. This technique, referred to as beach nourishment, is used to protect, restore or create the attractive wide beaches that are a main draw for tourists and locals alike. According to Dean, beach nourishment could protect the coast over the coming decades by counteracting erosion and building up beaches - until sea levels rise further and begin to actually submerge these areas. But nourishment projects are very expensive and last for only a few years at best; a single major storm can wash away a multi-million-dollar project in days. The process can also have major ecological drawbacks, such as burying important reef areas that act as nurseries for fish and other marine life.

In the longer term, the only defence strategies will be to raise land levels or build hard structures to hold back an advancing sea. However, concerns over beach erosion and degradation of turtle nesting sites have made hard defences unpopular with the public, and Florida law allows them only under specific circumstances such as imminent storm threat. Nevertheless, some say that sea walls and other hard structures will have to become more widespread if sea level rise is substantial. "I anticipate the entire shoreline of Florida will be seawalled within a couple of decades," says Pilkey. "I can't imagine it to be otherwise. I think sea walls will give some communities a few more decades, but without beaches."
Ultimately, even sea walls may prove ineffective at keeping the water out, as much of Florida has very porous limestone rock that sea water could travel beneath, leading to flooding, says Pilkey.

And not everyone agrees that hard defences and related strategies will provide a workable solution even in the shorter term. "Some coastal engineers, in Florida at least, have been a little arrogant and even disingenuous in saying, 'we can fix it," says Reed Noss, a conservation biologist at the University of Central Florida in Orlando, who recently organized a multidisciplinary Florida sea level rise conference. "Most other people who have looked at this issue geologists, oceanographers and so on - do not agree with that level of optimism." Dean argues that until solid data show actual rates of sea level rise in line with the more troubling projections, taking any drastic action would be reckless. "I think we've been guilty of being too sure of the future, and I think [this] raises the question of whether we're speaking without bias," he says.

Todd Walton, a coastal engineer at Florida State University in Tallahassee, agrees. "I have yet to see strong evidence from the data that sea level is going to be anywhere near as bad as some of the worstcase scenarios," says Walton, who recently coauthored an article ${ }^{6}$ with Dean on the topic. "As a result, I think one has to be rather cautious in planning." But Wanless and others say that engineers such as Dean and Walton are ignoring the potential contribution to sea level rise from the accelerated melting of ice sheets. "It's tragic that engineers are close to being in denial," says Wanless.

\section{CONSTRUCTION ZONE}

One thing everyone agrees on is that there is no simple answer for dealing with the myriad homes and high-rises lining most Florida beaches in the face of existing storm threats and an encroaching ocean. But rather than fortifying the coastline, one option would be to pull back a little. Laws could be written to stop development in areas scientists warn are too prone to eventual flooding and storm damage, limiting problems in a future, wetter Florida.

Here, too, the state has some prior experience to draw on. In 1970 Florida began blocking coastal construction within 15 metres of the mean high-tide level, a law some unscrupulous developers worked around by bulldozing dunes towards the ocean to increase their developable land. A few years later, the current Coastal Construction Control Line system started to take shape. The line's location is established for individual areas on the basis 
of the modelled present-day impact zone of a 100-year storm. Building seaward of this line is allowed, but it requires additional permitting and sturdier building practices. "I think the control line has been a resounding success in the state of Florida," says Dean. "It's pushed people back." But Pilkey believes the loopholes in current laws leave too many options open for building dangerously close to the water. "In effect, there are no restrictions on where you [can] build," he says.

In 1985 the state also established a separate, 30-year Erosion Projection Line, which is calculated by extrapolating the historic erosion rate at a given location. Large structures can't be built on the ocean side of this line, but in many cases private homes can. By law the line must be repositioned as the shoreline shifts, for instance after a major storm, but there is no provision for taking future changes in sea level into account.

There are numerous ways Florida could alter its building codes and practices to vastly improve sea level rise preparation, say academics, and the state need only look north for ideas. Maine, for instance, is considered by some to be among the US states best prepared for sea level rise - though its regulations on coastal development grew from a general fear of storms, rather than concern over climate change, says Joseph Kelley, chair of the Department of Earth Sciences at the University of Maine in Orono, who worked for the state of Maine when the laws were formulated. In Maine, strict laws forbid construction within a much larger flood zone than Florida's, and if a building is destroyed in a storm, it can be rebuilt only once. Larger buildings in Maine must be set back at least as far as erosion is expected to progress for 100 years. Florida, in comparison, has no set limit on rebuilding. In North Carolina, Pilkey's home state, there is also a stricter setback line for construction than Florida's. "We still have our problems," says Pilkey, "but we're light years from Florida."

\section{HIDDEN RISKS}

Economic incentives may be the most likely motivator to inspire major action on adaptation in Florida. If flood or wind insurance became impossible to get or prohibitively expensive for the beaches and other precarious locales, homes damaged in storms would in many cases have to be abandoned and coastal development would almost certainly be curtailed. But although that might seem a good and natural progression to some, it's unlikely to wash in a state that has taken a number of drastic actions to safeguard insurance coverage.
Currently, flood insurance - a virtual necessity for waterfront development - is offered only through the federal government and covers damage caused by rising waters including floods and breaking waves. Coverage is almost universally available, so it offers no impediment to building. Of even greater concern, says Young, is that the federal government sets no limit on the number of times it will rebuild power and transportation infrastructure after emergencies. "If people had to pay themselves to rebuild that entire infrastructure, then the values of their properties would probably be a little different," he says.

\section{"I don't see us abandoning Miami Beach, and I don't see the beach going away."}

Robert Dean

Moreover, in 2002 Florida's legislature created the government-run Citizens Property Insurance Corporation to underwrite policies for people who no longer qualify for private insurance and for others who opt in, thus further protecting waterside properties in vulnerable locations. Whenever the Citizens Corporation pays out more than it makes in premiums, every insured person in the state, including those with private insurance, pays a surcharge to make up the difference. That means even an elderly couple living on high ground in the middle of the state foots a portion of the bill for the damage caused to a waterfront mansion. With the risks of coastal development so effectively masked, some say it's likely that only a storm event of epic proportions would cause a rethink of policies in Florida. "People don't usually respond until some major event [happens]," says Murley.

Despite the absence of a state-wide strategy to change coastal development practices, some relevant activities are underway. The Florida Energy and Climate Commission, of which Murley is chair, is charged with implementing recommendations of a bold climate action plan completed in 2008 that calls for using state and local planning to actively discourage development that will be vulnerable to sea level rise. For the most part, however, action on the report's recommendations has been stalled, says Murley, because the commission is overwhelmed with administering energyefficiency grants funded by the recent national stimulus bill.

In 2006, the county of Miami established a climate change task force, and several other local governments have similar efforts underway. One of the first steps the Miami group recommended to city leaders was to purchase detailed topographic maps of the region so that areas likely to submerge under various sea level scenarios can be precisely mapped. "We're trying to get a rational plan for what we have to do at certain benchmarks of sea level rise," says Wanless, who cochairs the Miami task force's science and technology committee.

Other entities within the state also may get involved in addressing sea level issues beyond business and residential construction. The South Florida Water Management District, for example, is drawing up phased plans to address infrastructure upgrade and replacement needs under various sea level rise scenarios. But when it comes to Florida's main challenge, development, a phased approach is less tenable, because development can be prevented or altered much more easily and cheaply than it can be reversed. One option is for the government to purchase land and set aside areas for ecological purposes. Though some endangered species' entire habitats could be lost, in other cases strategic land purchases could create retreat corridors that would allow animal populations to survive.

Wanless points out that given the concentration of the state's population on coasts, areas for human retreat will be an even more monumental concern with substantial sea level rise: millions of Floridians could ultimately be displaced. "This is going to become an increasingly risky place to live towards the end of the century," says Wanless, who believes that large areas of land will eventually have to be abandoned. Nobody really knows how to develop an infrastructure that can handle sea level rise at the upper end of the projected rates, he says. "We may all eventually be living in trailers and houseboats."

Published online: 6 April 2010

doi:10.1038/climate.2010.27

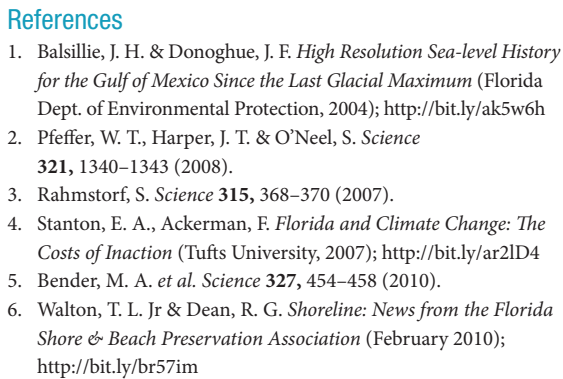

1. Balsillie, J. H. \& Donoghue, J. F. High Resolution Sea-level History for the Gulf of Mexico Since the Last Glacial Maximum (Florida Dept. of Environmental Protection, 2004); http://bit.ly/ak5w6h

2. Pfeffer, W. T., Harper, J. T. \& O’Neel, S. Science 321, 1340-1343 (2008).

3. Rahmstorf, S. Science 315, 368-370 (2007)

4. Stanton, E. A., Ackerman, F. Florida and Climate Change: The Costs of Inaction (Tufts University, 2007); http://bit.ly/ar2lD4

5. Bender, M. A. et al. Science 327, 454-458 (2010).

6. Walton, T. L. Jr \& Dean, R. G. Shoreline: News from the Florida Shore \& Beach Preservation Association (February 2010); http://bit.ly/br57im

Mark Schrope is a freelance writer based in Florida. 